\title{
El rock como eje de un lenguaje poético (Perú, 1968-1988)
}

\section{Rock music as the axis of a poetic language (Peru, 1968 - 1988)}

\author{
Lisa Carrasco La Cruz' \\ Universidad Científica del Sur, Perú \\ lisa.carrascolacruz@gmail.com \\ ORCID 0000-0002-9181-9809
}

Citar como: Carrasco, L. (2019). El rock como eje de un lenguaje poético (Perú, 19681988). Desde el Sur, 11(2), pp. 107-126.

\section{RESUMEN}

La investigación propone que el rock, que trajo consigo un discurso de rebeldía y vitalismo, significó uno de los ingredientes principales para la formación de un nuevo registro expresivo en la vertiente conversacional de la poesía peruana durante 1968 hasta 1988. A este registro se le ha denominado «lenguaje rock». Se describen y explican las características de este y se realiza un análisis de fragmentos de poemas que conforman un corpus que se propone como representativo. Además, se pone en evidencia la necesidad de impulsar una crítica literaria interdisciplinaria que investigue las relaciones entre diversos lenguajes artísticos.

\section{PALABRAS CLAVE}

Poesía, rock, lenguaje, Perú

\section{ABSTRACT}

This research proposes that rock music, with its associated discourse of rebellion and vitalism, constituted one of the main ingredients in the formation of a new expressive

1 Licenciada en Literatura por la Universidad Científica del Sur. Ha publicado artículos, relatos y poemas en las revistas Camaleón Paranoico, Kill the Zine Fanzine, Austro y en la web de Poesía Sub25; además, participó en la antología El amor trasciende el tiempo y el espacio (2019) de esa misma editorial. Asimismo, ha publicado reseñas, crónicas y entrevistas en Molok, revista virtual de la que es codirectora (revistamolok.com). Ganó los juegos florales en su casa de estudios en la categoría de cuento (2016). Recibió una mención honrosa en el concurso «El cuento de las 1000 palabras» de la revista Caretas (2016). Ha participado como ponente en diversos congresos de humanidades, con intervenciones que abordan las correspondencias entre distintos lenguajes artísticos. 
register, contributing to the conversational aspect of Peruvian poetry from 1968 to 1988 . This form has been called «rock language». In this study, we describe and explain the characteristics of this poetic form and analysis fragments of poems from the corpus which might be considered representative. In addition, we highlight the need to encourage interdisciplinary literary criticism as a method of investigating the relationships between diverse artistic languages.

\section{KEYWORDS:}

poetry, rock, language, Peru

El siglo XX constituye un gran quiebre en la historia de la humanidad. Dos guerras mundiales causaron grandes crisis económicas, políticas y culturales. Los cimientos sobre los cuales el mundo estaba construido se removieron para siempre. Dice el historiador Eric Hobsbawm en su importante libro Historia del siglo XX: «El siglo XX no puede concebirse disociado de la guerra, siempre presente aun en los momentos en los que no se escuchaba el sonido de las armas y las explosiones de las bombas» (1998, p. 30).

La Segunda Guerra Mundial dejó en carne viva una serie de conflictos raciales, políticos e identitarios, que se mantuvieron latentes con la llegada de la denominada Guerra Fría en 1947. Durante este periodo, en que se temía un nuevo enfrentamiento armado de enormes proporciones, surgió un fenómeno que el ya mencionado Hobsbawm describió como el baby boom.

La tasa de natalidad, sobre todo en Europa y Estados Unidos, se incrementó en grandes cantidades y generó rápidamente el desarrollo de una nueva generación. Esta, a su vez, sería la causante de una serie de revoluciones culturales, políticas y sociales. Desde sociedades resquebrajadas surge la necesidad de un cambio.

Las revoluciones las lideraron los jóvenes. Al verse insertos en una realidad que luchaba por reconstruirse, decidieron tomar partido $y$, desde su forma de entender el mundo, marcar una nueva pauta. Es así como se construye una nueva cultura juvenil. Los blue jeans, el cabello largo y las excentricidades que los caracterizaban generaron un nuevo sistema comercial que crecía y se alimentaba de su curiosidad y su deseo de innovar. Las disqueras, las tiendas de ropa y de arte, los cines y cualquier lugar público ofrecían ahora contenido para jóvenes, muchos de los cuales ya no dependían económicamente de sus padres. 
Al respecto, Elena Piñeiro afirma en una ponencia sobre las culturas y contraculturas de los sesenta:

La juventud era funcional a la expansión de la producción. La cultura juvenil se convirtió en dominante en todas las economías desarrolladas, porque los jóvenes habían aumentado su capacidad adquisitiva. Además, contribuyó a socializar a sucesivas generaciones de adultos que quedaron marcados por esta experiencia, fijó sus pautas de consumo y los llevó a asumir, primero tímidamente y luego con total desenfado, las modas impuestas por los jóvenes. Los vaqueros y el rock se convirtieron en símbolos de la modernidad juvenil. La cultura juvenil se internacionalizó e impuso la hegemonía cultural norteamericana en todo occidente (2009, p. 3).

El nuevo sistema de producción que describe Piñeiro se verá impulsado por la influencia particular de un género musical que trajo consigo el espíritu de la época. El rock nació en el momento en que se encontraron el country y el rhythm and blues. El primero es un género «esencialmente de raíces blancas y orígenes rurales. Reagrupa todas aquellas expresiones típicas de algunas regiones de Estados Unidos, víctimas de una pobreza endémica» (Landínez, 2014, p. 30). Con el sonido de guitarras, banjos y violines, el country recrea la realidad sureña de raíces caucásicas mediante melodías festivas de tonadas pegajosas. Se convirtió en una parte importante del rock cuando se mezcló con el otro género que representa una minoría marginada en el país.

El rhythm and blues nace entre los esclavos afrodescendientes de las plantaciones de algodón en el sur de Estados Unidos. Sus ritmos se mezclan más tarde, tras la llegada de la libertad y las migraciones de la Segunda Guerra Mundial, con sonidos heredados de distintas partes del mundo. El saxofón, el piano, la batería y la guitarra construyen un ritmo potente y desenfrenado que se encuentra con el country cuando la televisión invade los hogares estadounidenses. Así surge el rock. Su discurso iconoclasta fue rápidamente aceptado por las comunidades juveniles de todo el mundo. Los medios de prensa se encargaron de correr la voz acerca de esta extraña moda que definía una nueva visión del mundo. Así, en 1955, se oye por primera vez una canción de rock en Lima. Era el estreno de la película Blackboard Jungle, dirigida por Richard Brooks, un 28 de agosto a mediodía.

Los limeños comenzaron a contemplar la rebeldía. Las canciones, alegres y pegajosas, sonaban una y otra vez en la radio. Pero es en 1957 cuando el rock de América del Sur nace oficialmente. Según el escritor Carlos Torres Rotondo: «Todo ocurrió rápidamente y en un solo verano, el primer verano del rock en Hispanoamérica» (2009, p. 27). A partir de este 
momento los jóvenes peruanos volvieron la mirada hacia el rock y admitieron su discurso y prácticas como propios. Luego de unos años, este género ya formaba parte de su vida y, por lo tanto, de su lenguaje.

Esta investigación se propone estudiar la influencia del rock sobre un grupo de poetas de la vertiente conversacional de la poesía peruana durante el periodo de 1968 hasta 1988. Si bien ya en años anteriores era posible observar que la poesía viraba su discurso hacia referentes de la cultura de masas y un estilo más conversacional, podemos decir que aún sostiene una relación con los tópicos y el lenguaje propios de la generación del 50, que estaba muy influenciada, a su vez, por la poesía europea. Así, es desde 1968 que apreciamos un cambio de paradigmas en la escritura poética. Al respecto, José Rosas Ribeyro, en su ensayo «Estación reunida, el grupo sin grupo", sustenta, en contra de la visión historicista de la crítica que usualmente agrupa a las generaciones poéticas cada 10 años, por qué debemos considerar una nueva generación la que se fundó en 1968:

en el campo de la poesía la generación del 68 introdujo el coloquialismo, la ironía, la narratividad, la apertura a los más diversos referentes culturales — siendo el más importante el de la poesía anglosajona-, la utilización poética de todos los niveles del habla, la fusión entre lo histórico y social y la experiencia individual (2007).

Esta precisión permite que esta investigación se refiera al grupo al que pertenecen los poetas estudiados como «generación del 68». Sería desde aquel año, entonces, donde percibimos en dicho grupo de poetas un cambio de actitud fundado por el rock². Algunos de ellos, que colaboraban en Estación reunida, como Óscar Málaga y José Rosas Ribeyro, comenzaron a preparar sus propios libros. También Manuel Morales edita sus Poemas de entrecasa. Este libro es particularmente importante, pues refleja el inicio de una actitud distinta. Los textos que nos ofrece Morales están cargados de humor y de expresiones coloquiales. Su visión irónica de la autoridad es un modelo de la poesía que vendría poco tiempo después.

Durante los años siguientes seremos testigos de la aparición de libros que manifiestan el cambio de actitud descrito por Rosas Ribeyro. El rock se convierte en un elemento principal para la construcción de estas poéticas. Esto permite afirmar que a partir de 1968 podemos hablar del

2 En una entrevista al poeta Roger Santiváñez, le preguntamos por el cambio de paradigmas que trajo consigo el rock. Su respuesta fue: «Por supuesto que el rock cambió a toda la generación que surgió con él. El rock se convirtió en una actitud, una manera de ser de aquella generación. Apareció el concepto y la realidad nueva de la existencia del joven rebelde y maldito. Eso no existió antes del rock. A Piura llegó en 1968 o 1969 Jean Paul, el Troglodita, y cambió a la juventud piurana de esa época» (2018). 
nacimiento de un «lenguaje rock». Definimos esta categoría como el lenguaje que posee un grupo de poetas de la generación de 1968 que comparten una serie de rasgos articulados alrededor de la influencia del rock; esto permite una nueva lectura de la tradición de poesía conversacional en la que están inscritos. Entre ellos tenemos a Roger Santiváñez, integrante de los grupos poéticos Hora Zero, La Sagrada Familia y Kloaka; a Enrique Sánchez Hernani, perteneciente a La Sagrada Familia; y también a Juan Ramírez Ruiz, Enrique Verástegui y Jorge Pimentel, miembros de Hora Zero.

Esta investigación culmina en 1988 con la publicación de El chico que se declaraba con la mirada, de Roger Santiváñez. La poesía que se publica en años posteriores, si bien aún manifiesta la influencia del rock (esto se hace evidente en los casos de los poetas Domingo de Ramos o Monserrat Álvarez), principalmente muda sus intereses hacia otros referentes temáticos que surgen en el contexto, como la violencia política, y hacia otras exploraciones con el lenguaje, desde donde surgen estilos como el neobarroco.

En el Perú existen muy pocas publicaciones críticas respecto del tema que ocupa esta investigación. En realidad, si tomamos en cuenta la cantidad de estudios literarios en general, aquellos que poseen un abordaje interdisciplinario ocupan un menor porcentaje. Esto permite afirmar que existe una deuda de la crítica en relación con este tipo de enfoques. Se considera necesario, por tanto, plantear la necesidad de que exista mayor interés crítico en estudiar los vínculos entre dos o más artes, pues los resultados pueden generar valiosa y novedosa información.

Carlos Torres Rotondo y José Carlos Yrigoyen escribieron el único libro que aborda el tema de esta investigación. Se trata de Poesía en rock, editado en 2010. No solo es la primera antología de poesía rockera peruana, sino que además reúne los testimonios de los protagonistas de esta época, los poetas, que van reconstruyendo la relación personal que mantuvo cada uno con el rock. Consideramos que este libro es un aporte importante y partimos desde sus alcances para realizar nuestra sistematización del lenguaje rock.

El tema que sí ocupa gran cantidad de estudios es la tradición de poesía conversacional, que es donde se inscribe la poesía que estudiamos. Se ha definido este estilo como una escritura coloquial e irónica que busca apelar al lector. La escritora española Carmen Alemany ha realizado varios estudios respecto de esta categoría. Ella afirma que:

se trata de una poética diferenciada de la que se venía creando en Hispanoamérica: existe un afán de llegar al lector e implicarlo, de 
aludirlo y no eludirlo [...] Esta forma diferencial de escritura se funda en la exploración del potencial lingüístico; no se trata de convertir al texto en único centro de atención, en el acto único de la escritura, sino, por el contrario, de remitir el elemento ficcional a un contexto fuera de la propia obra con el propósito de «decir algo más» a través de la palabra, que pasa a convertirse en plurisignificacional (1997, p. 49).

Dicho esto, podemos entender lo conversacional, precisamente como su nombre lo refiere, como la tarea poética que establece un diálogo con el lector y que emplea un lenguaje cotidiano en ese afán. Los lectores ideales de esta poesía no son especializados. Es justamente aquella la intención de esta escritura: descender del pedestal. Esto no quiere decir que la calidad de lo escrito sea inferior, sino que su criterio estético es distinto.

Como se ha indicado, los poetas estudiados en esta investigación pertenecen a la vertiente conversacional de la tradición poética peruana. Por lo tanto, es posible afirmar que el lenguaje rock no posee en su mayoría características distintas de las que definen la poesía conversacional, sino que estas características se articulan de manera enfática en torno a la presencia del rock y la visión del mundo que este trajo consigo. En ese sentido, este estudio permite generar una nueva lectura de la escritura conversacional.

Es importante recalcar que, a diferencia de otras poéticas en Latinoamérica, en el Perú el rock tuvo un impacto más profundo en el imaginario de los poetas, y esto se evidencia en su escritura, lo que permite sistematizar su producción y proponer en torno a este fenómeno la categoría de lenguaje rock.

Para sostener la afirmación de que el rock configuró un nuevo lenguaje, en este estudio se emplean soportes teóricos musicales que brindan alcances acerca de la estructura del rock. Esto permite establecer una comparación con la estructura de los poemas analizados, y así llegar a la conclusión de que ambos lenguajes artísticos mantienen muchos puntos en común. Asimismo, se emplean herramientas de la teoría literaria y los estudios culturales. Estos referentes nos permiten obtener una visión integral del fenómeno estudiado.

Reconocemos que el lenguaje rock, como categoría, posee tres características principales. La primera es la heterodoxia del sujeto; la segunda, la formación de una identidad juvenil y hedonista; la tercera, una marcada exaltación del presente. Dichas características poseen, a su vez, subrasgos que iremos explicando cuando sea pertinente. A continuación, el análisis de los poemas que conforman el corpus de poesía rockera, y la explicación de los rasgos que esta posee. 


\section{Heterodoxia}

La heterodoxia del sujeto poético rockero se manifiesta en su actitud disidente respecto de las normas y paradigmas sociales. Notamos que se reconoce al margen y posee un discurso iconoclasta que rechaza y visibiliza las grietas del sistema político y económico que lo rodea. La característica más evidente de esta heterodoxia es el visible problema de comunicación con generaciones anteriores que se traza. Procederemos a explicar este rasgo.

\section{Problema de comunicación con generaciones anteriores}

Una de las manifestaciones principales de la heterodoxia del lenguaje rock se evidencia en el marcado choque generacional que se produce cuando la visión del sujeto poético se enfrenta a la que sostienen aquellos que son distintos de él, es decir, los adultos. Como ya se ha mencionado, desde la década de 1950, gracias a diversos fenómenos políticos y económicos, se produce un enfrentamiento cultural ${ }^{3}$. Los productos y el contenido para jóvenes, que cada vez van más en aumento, se ven enfrentados con la ortodoxia de un sistema que no reconoce su presencia. Dos fuertes puntos de vista se enfrentan. En tal sentido, la poesía que estudiamos se apropia de ese choque generacional, que es un factor clave dentro del imaginario rockero.

En el poema «Heavy rock», perteneciente al poemario Banda del sur, de Enrique Sánchez Hernani, podemos leer los siguientes versos:

ebrios sin sentido ni dinero y odiábamos a nuestros padres porque nos obligaban a cortarnos el pelo sabiendo que Hendrix había muerto $(1985$, p. 13).

La voz poética se define a sí misma como una conciencia juvenil que marca su distancia con aquellos que representan la autoridad: sus padres. Reconoce que no posee bienes materiales y tampoco persigue grandes objetivos, a diferencia de lo que se le exige. Los padres ejercen su poder de manera represiva y el enfrentamiento cultural se hace evidente. El rock constituye no solo el motivo por el que se enfrentan el adulto y el joven,

3 Esta búsqueda de justicia y crítica de lo establecido es una muestra del ánimo de la época, como indica Luis Chueca en su artículo «Alcances y límites del proyecto vanguardista de Hora Zero»: "Se trata de un tiempo de juventudes altamente politizadas que confiaban en la revolución «a la vuelta de la esquina». De esos ánimos de época —o de esa estructura de sentimiento, para usar la conocida expresión de Raymond Williams-, que no solo se corresponden a lo hecho por la primera fase militar, se nutrió el optimismo de Hora Zero: para sus integrantes, cuyo diagnóstico del país y de la poesía no dejaba de denunciar el caos y la tragedia, todo era posible, como lo evidencian sus manifiestos y la poesía de su primera etapa» $(2000$, p. 38$)$. 
sino que también es el discurso desde donde este último responderá. En el mismo poema, podemos leer en los últimos versos:

No volvimos nunca a las aulas

nos encerraron en celdas llenas de chinches y sabandijas nos arrancaron los jeans

amenazaron con hacer de nosotros hombres y mujeres razonables que amasen a su patria y pudiesen morir sin gemidos por su bandera

y una lenta canción nos devolvió el recuerdo de nuestros discos desvaneciéndose en los armarios

heridos por el sol

y el insoportable ruido de nuestros sueños (1985, p. 15).

Los versos citados reflejan el enfrentamiento que hemos mencionado. El sujeto poético grafica una situación de encierro en donde la autoridad ejerce su poder mediante la destrucción. El tercer verso es muy descriptivo en ese sentido: los jeans son prendas relacionadas con tendencias juveniles y en el rock son una constante. Al afirmar que le fueron arrancados, la voz poética grafica la situación de violencia a la que se ve expuesta debido a que posee paradigmas distintos. El verso siguiente es más contundente pues plantea la aparición de la razón como una amenaza, es decir, como la lógica negativa de un sistema que no los comprende pero sí los castra. El patriotismo y las responsabilidades serán, entonces, signos de razón y de adultez. Por lo mismo, son todo aquello en lo que el sujeto poético no desea convertirse. Estamos frente a un nuevo sistema de valores. Es interesante que el poema culmine con la aceptación de que estos sueños rockeros tienen una carga de «ruido» que es «insoportable». El choque cultural es fuerte y los adultos nunca lo comprenderán ni soportarán.

En el poema «Datzibao», perteneciente al poemario En los extramuros del mundo, de Enrique Verástegui, leemos los siguientes versos:

y meapretécontratibuscando desesperadamenteencontrarmeen tus ojos y amé todas tus cosas

y tu mirada angustiada y esa seriedad para responderme a ciertas preguntas y cuestiones que nos diferenciaron para

siempre de las personas nacidas antes de 1950 (1971, p. 27).

La descripción de la relación que mantiene el sujeto poético y su compañera es vertiginosa. Somos testigos de su agilidad y cómo sus acciones se ven impulsadas por sus deseos. El imaginario juvenil que se nos muestra está definido por sus palabras: la expresión «amé todas tus cosas» nos remite, debido a su ambigüedad, a un conjunto de valores inexactos, no 
completamente definidos, pero que son motivo del afecto y deseo del yo poético. Esa es la manera en la que se manifiestan sus pasiones. Existe una marca temporal que lo sitúa en un determinado momento y que define su discurso: el último verso citado da cuenta de la distancia que existe entre los nacidos antes de 1950 y los que lo hicieron después. Estos últimos serán los que se enfrenten a aquellos, pues su manera de comprender el mundo y lo que en él sucede será distinta; su sistema de valores, otro. Esto también sucede en el rock, donde la figura de la autoridad está generalmente relacionada con una determinada edad. Los adultos, debido a que responden a otro tiempo, poseen prioridades y criterios distintos. El problema de comunicación entre generaciones queda al descubierto.

Así como los poetas rockeros de la generación del 68 se rebelan ante la autoridad, muchos de ellos también defienden su propio discurso político ${ }^{4}$. Esto se manifiesta en textos que describen con un tono irónico y crítico la realidad que los rodea. Por ejemplo, en el poema «Si te quedas en mi país», perteneciente al poemario En los extramuros del mundo, de Enrique Verástegui, podemos leer los siguientes versos:

no hay dónde ir

en mi país

pero tienes que ir saliendo

como el acné en el cascarón rosado.

Y esto te urge más que una palabra perfecta.

[...]

Porque una lengua hablará por tu lengua.

y otra mano guiará a tu mano

si te quedas en mi país (1971, p. 29)

La opinión política se hace presente en este poema. Esta vez, el sistema literario es descrito como un sinsentido que genera presión en los jóvenes poetas y que los obliga a migrar o a transformar su discurso según convenga. Esto se aprecia en los primeros versos citados, donde se plantea una paradoja: no se puede salir del país, pero hay que ir saliendo. Ese sentimiento contradictorio es parte de un espíritu rebelde y convulsionado rockero, que realiza un recorrido caótico, errático, y se apropia

\footnotetext{
4 Por ejemplo, el manifiesto «Pronunciamiento del movimiento Hora Zero sobre cuatro puntos actuales», recogido por José Miguel Oviedo en su libro Estos 13, dice: «Nosotros afirmamos que el pueblo cubano y sus dirigentes han hecho muy bien en tomar las medidas necesarias para que Cuba prosiga en su proceso revolucionario, y siga siendo el primer y único territorio libre de América. Un escritor es condenable cuando atenta con su vida y con su obra contra la seguridad de millones de seres humanos, y es no condenable cuando su posición y sus miras están fundidas con las aspiraciones de esos millones de seres humanos, anteponiendo los intereses del pueblo al propio» (1973, p. 134).
} 
de la ciudad. Con un tono irónico y crítico este poema plantea una posición rebelde frente al sistema que lo contiene. La disposición de los versos también grafica ese sentir contradictorio o caótico del yo poético.

\section{Identidad juvenil y hedonista}

Es posible afirmar que el discurso poético rockero es enunciado desde una identidad juvenil, que asume su tiempo como un eje para generar un cambio de paradigmas. El sujeto poético se reconoce diferente respecto de los adultos y esta distancia lo llevará a ponerse a prueba constantemente. Busca llegar al límite de sus sentidos para, de ese modo, obtener nuevas formas de conocimiento. Algunas de las características de la identidad juvenil y hedonista del sujeto son la experimentación con alcohol y drogas y la presencia de sus primeras y desenfrenadas experiencias sexuales. A continuación, explicaremos estos rasgos.

\section{Experimentación con alcohol y drogas}

La búsqueda hedonista de nuevas experiencias sensoriales mediante drogas y alcohol llevan al límite al sujeto lírico, que constantemente acude a ellos para extralimitar sus sentidos. Se trata de una búsqueda de placer y de distintos niveles de conciencia. El discurso poético que ofrece aparece configurado desde la influencia de estos estupefacientes.

Al ser consultado sobre el uso de drogas en su proceso de escritura, en una entrevista que le realizaron en 1965, el poeta beat Allen Ginsberg, una de las más grandes influencias para la generación poética que se estudia, afirmó:

obviamente las drogas fueron una técnica para experimentar con la conciencia, para obtener áreas diferentes y niveles diferentes y similitudes diferentes y reverberaciones diferentes de la misma visión. [...] Bueno, resumiendo, las drogas me fueron útiles para explorar las percepciones, las percepciones sensoriales y para explorar las diferentes versiones de petites sensations, y fueron útiles para escribir en algunas ocasiones, bajo su influencia (1981, pp. 286-288).

El escritor reconoce que el empleo de drogas genera un estímulo particular en los poetas que tienen a su alcance imágenes y conceptos que, estando en un estado sobrio, quizás no percibirían. Podemos afirmar, entonces, que la decisión de experimentar con drogas y alcohol responde también a necesidades de experimentar con el lenguaje y ponerlo a prueba. En el mismo sentido, en el rock el empleo de drogas y alcohol es recomendado como un aliciente para la creación; asimismo, constituye una de las prácticas más imitadas relacionadas con la diversión y la experimentación sin mesura en contraposición con los límites del sistema. 
La experiencia creativa estimulada es una práctica que alcanza una trascendencia simbólica dentro del imaginario rockero, lo que la convierte en una referencia imprescindible para los poetas que singularizan el estilo conversacional desde aquel imaginario.

En el poema «Cruzando la Pza. de Armas en un gran vacilón», perteneciente al poemario Canciones desentonadas y alegres aterrizajes para evitar el suicidio, de Óscar Málaga, podemos leer los primeros versos:

Cruzando la Pza. de Armas

con los ojos reventados, las manos

como un violento choque de automóviles

destrozados sobre mi visión atascada

sobre balcones, sobre viejos cojines

de lana, de lana (2016, p. 53).

El sujeto poético reconoce desde los primeros versos que se encuentra bajo los efectos de las drogas. Al señalar que posee «los ojos reventados», se genera una atmósfera en donde todo lo que va construyendo es producto de su estado. Se describe una situación fragmentada, las acciones que discurren son violentas y su lenguaje es jergal. El discurso poético refleja la agilidad con la que el sujeto percibe la realidad. Interesante es señalar que el hecho de poseer una marca física del estado en que se encuentra —es decir, el hecho de tener «los ojos reventados»— constituye motivo de cierto orgullo para él, pues al ser uno de los primeros datos que nos ofrece sobre sí mismo, define la manera en que el lector lo percibirá. Se trata, entonces, de un sujeto que elige presentarse como un elemento disidente, que habla de sí mismo y reconoce su transgresión.

En el poema «Razón de silencio», de Manuel Aguirre, podemos leer los siguientes versos:

el desempleo absoluto la negativa total a peinarse con un limpio-peine por otro lado nos gusta la hierba el alcohol y el recatado acto de fornicar (2010, p. 292).

En los versos citados el sujeto poético se refiere de forma directa a las drogas y el alcohol. Del mismo modo que con el poema de Málaga, el hecho de afirmar frontalmente su gusto por estos elementos refleja la construcción de una identidad juvenil y disidente, que reconoce su diferencia y la celebra. Poetizar sobre las drogas y el alcohol es una marca del cambio generacional y es una constante en el lenguaje rock que da cuenta de una 
búsqueda de exploración literaria y también del deseo de experimentar diversas formas de extralimitar los sentidos ${ }^{5}$.

Es pertinente mencionar que, en el poema de Aguirre, el sujeto habla en plural para definir sus gustos. Es decir, habla en nombre de un colectivo. Como se ha indicado, la poesía que estudiamos se inserta en la tradición de poesía conversacional hispanoamericana, en donde se plantea el nacimiento de un sujeto poético que recoge distintas voces. En este caso el sujeto poético habla en nombre de los jóvenes a quienes representa, y se puede afirmar que este colectivo representa, a su vez, un nuevo tiempo.

La poesía conversacional se apropia del contexto del sujeto poético. En el caso peruano - y también en otros países de Latinoamérica- lo conversacional se encuentra con el rock. El resultado es una poesía coloquial y urbana, musical y estridente. Podríamos Ilamarlo conversacionalismo rockero. El sujeto poético plasma esta estética en su lenguaje.

\section{Primeras y desenfrenadas experiencias sexuales}

Otra manifestación de esta identidad juvenil y hedonista es la experimentación sexual desenfrenada. Como se ha mencionado, se trata de un sujeto joven que, del mismo modo como sucede con el alcohol y las drogas, está interesado en explorar su sexualidad de todas las formas posibles y en oposición a lo que le indique el sistema. Somos testigos de un discurso poético que acompaña estas experiencias, que en ocasiones son iniciáticas, y notamos, de igual forma, todos los estados emocionales por los que atraviesa el sujeto en este proceso. En tal sentido, y tal como se precisó en el rasgo anterior, la sexualidad fue identificada también como una práctica que alimenta la simbología del imaginario rockero, y por eso mismo pasa de ser una exploración íntima a una forma de posicionar al sujeto poético en términos contestatarios. Los autores que matizan el registro conversacional desde una visión rockera comprenden que poetizar la sexualidad es una manera de ganar una identidad y resistir desde esta.

En el poema «1», de Roger Santiváñez, perteneciente al poemario EI chico que se declaraba con la mirada e incluido en la antología Dolores Morales de Santiváñez, podemos leer en los versos finales:

5 El consumo de drogas, asimismo, representó un acto de posicionamiento contestatario frente a la autoridad. Al respecto, el historiador Eric Hobsbawm afirma en su libro Historia del siglo XX: «el consumo de drogas era, por definición, una actividad ilegal, y el mismo hecho de que la droga más popular entre los jóvenes occidentales, la marihuana, fuese posiblemente menos dañina que el alcohol y el tabaco, hacía del fumarla (generalmente, una actividad social) no solo un acto de desafío, sino de superioridad sobre quienes la habían prohibido» (1994, p. 335). 
Ellos piensan que yo ya fui. No saben que es la primera vez, aunque se los he insinuado. Cada quien se pierde en el silencio. La puerta cerrada.

Desvístete.

Ella se sorprende cuando le cuento que es la primera vez. Acércate dice, coge el falo dormido, lo corre y lo aprieta despacio, alumbra con una linterna de otorrinolaringólogo. Otra vez. Ya, sonríe. Su vientre avanza y se estrecha al mío. Hay música (2006, p. 59).

La descripción de la experiencia sexual iniciática constituye para el sujeto poético un proceso singular, que le exige que se despoje de algunas sensaciones como la vergüenza. Notamos que el tono íntimo del discurso ofrece también una carga de ingenuidad. Su falta de experiencia define su identidad juvenil. Sin embargo, este tono íntimo se complementa con un acto público. Se afirma que existen otros sujetos frente a los cuales el joven debe legitimar su virilidad informándoles de la consumación del acto. De modo que la experiencia sexual tiene un lado íntimo pero también otro de reafirmación social colectiva. Es pertinente destacar el tono narrativo del registro conversacional del poema. Este estilo ilustra mejor el carácter íntimo-testimonial del discurso poético.

En el rock también encontramos narraciones de experiencias sexuales de este tipo, pues su discurso defiende la libertad de experimentar. El último verso citado retrata el ambiente en el que se desarrolla el acto sexual: se trata de un prostíbulo donde está sonando una canción. El rock, entonces, se inserta en el poema como el marco de esta nueva experiencia6 .

En el poema «Datzibao», de Enrique Verástegui, podemos leer los siguientes versos:

Lo perfecto consiste en desabotonarnos el torso mientras vamos salvajemente penetrando en esta selva de arenas movedizas y tu vida o mi vida no ruedan como esas naranjas plásticas que eludimos porque tú y yo somos carne y nada más que un fuego incendiando este verano.

La vida se abre como un sexo caliente bajo el roce de dedos reventando millares de hojas tiernas y húmedas, y no dijimos nada pero exigíamos a gritos destruir la ciudad (1971, p. 27).

\footnotetext{
6 Sobre la injerencia de los códigos musicales en la poesía, Enrique Verástegui dijo a Wolfgang Luchting en una entrevista en 1977: «Si nos ponemos a analizar los códigos de la poesía, de la narración y el teatro, vamos a ver que en estos momentos se están constituyendo en lecturas de formas musicales» (p. 336). Y es interesante pensar en el poema de Verástegui como una composición musical, rítmica, que refleja la aceleración de la ciudad al transcribir en su cadencia este caos.
} 
En los versos citados notamos que la descripción del acto sexual es acelerada y directa. Las referencias con las que se construye el discurso nos remiten a escenarios exóticos y calurosos, pero también llenos de peligro, como la selva y las arenas movedizas. El acto sexual se identifica con estos referentes: es definido, literalmente, como «fuego». El sujeto poético encuentra satisfacción en esta aceleración. El primer verso citado así lo demuestra, cuando define el acto como «lo perfecto». Iguamente, al definirse a sí mismo y a su compañera de acto como «carne», se puede entender que las pulsiones sexuales de ambos están elevadas y son las que generan aquella experimentación desenfrenada. La experiencia del sexo será para el sujeto un espacio íntimo en donde buscará satisfacer su hedonismo. El último verso es revelador, porque se contrapone la palabra o la ausencia de esta («no dijimos nada») con el grito o el gemido, tratándose de un escenario sexual, que es el lenguaje desde el cual se confronta al sistema. Entonces, la imagen del grito sexual aparece como una reacción rebelde y un posicionamiento disidente. El elemento del grito, tan característico del lenguaje rock, será desarrollado algunas páginas más adelante.

\section{Exaltación del presente}

Como está señalado anteriormente, el sujeto poético reconoce su juventud como eje de su diferencia. Esto lo lleva a pensar en el presente como la única instancia temporal que le interesa. El pasado está estático y es lo nuevo, lo inmediato aquello que llamará su atención y sobre lo que recaerá su búsqueda creativa. Una característica propia de la exaltación del presente es la coloquialidad transgresora de la poesía rockera.

\section{Coloquialidad transgresora}

Una de las principales características del registro expresivo del lenguaje rock es su coloquialidad transgresora. Se manifiesta en jergas y términos tomados del habla coloquial urbana de Lima, que son empleados por un sujeto poético juvenil y contracultural que posee una visión heterodoxa de la realidad en la que se encuentra. El rock como género musical también ha manifestado esta coloquialidad. En su afán antisistema, se caracteriza por emplear un lenguaje coloquial y en ocasiones obsceno, que pueda ser fácilmente repetido por todos. Esta influencia se hará evidente en la poesía. Al respecto, Reinhard Huamán afirma en un ensayo sobre la poesía de Óscar Málaga:

Pero lo que más llama la atención en estos poemas es el uso del lenguaje. En él notamos un coloquialismo en estado natural, [...] se presenta intencionalmente en su materia bruta, sin la elegancia de 
sus pares del 50, es un habla criolla, vivencial y por ende directa, callejera y violenta por momentos. En suma, un lenguaje reproducido con la ira y la satisfacción «de quien estampa un obsceno graffiti en el baño» (2006).

Huamán hace hincapié en que la coloquialidad transgresora de la poesía de la generación del 68 se debe a un cambio de paradigmas éticos y estéticos respecto de las generaciones anteriores y refleja la agilidad con la que el sujeto poético se desplaza. Es un lenguaje directo y joven, que no está adornado con eufemismos y retrata la realidad tal y como se percibe: caótica. Desde nuestra perspectiva, este rasgo, que puede ser identificado como una característica natural o propia del registro conversacional, sí toma una mayor relevancia o logra una mayor exploración desde las voces poéticas que identificamos como parte de una estética rockera.

Notaremos la presencia de algunas onomatopeyas en la poesía rockera, que también están presentes en el rock. Sobre ello, Héctor Fouce indica:

los instrumentos de análisis de la música clásica (armonía, melodía) no son capaces de explicar completamente la música popular. El uso del volumen y la distorsión en un grupo como Metallica (timbre) o los contrastes entre estrofas relajadas y retornos ruidosos de Nirvana (dinámica) influyen poderosamente en nuestra manera de sentir la música y darle sentido (2015, p. 34).

Es posible afirmar, por lo tanto, que para estudiar la poesía rockera no solo debemos reparar en sus componentes clásicos musicales, como la armonía o la melodía, sino que existen otros elementos como la distorsión, las onomatopeyas y el trabajo con el volumen que aportarán sentido al texto.

En el poema «Los reinos de Max Factor», de Luis Alberto Castillo, que aparece en el poemario Melibea \& otros poemas y es recogido en el libro Poesía en rock, de Carlos Torres Rotondo y José Carlos Yrigoyen, podemos leer en los primeros versos:

\section{Era}

de

john paul george \& ringo

henos aquí luciérnagas

sorbiendo el vino con k-ñitas

lánguidos

sucios (2010, p. 304) 
La consonante $k$ se inserta en un neologismo que reemplaza a la palabra cañitas. Esta tendencia refleja la existencia de un nuevo paradigma estético, que genera mediante estas palabras, que son reinvenciones, la actualización del lenguaje hacia un nuevo registro juvenil, fragmentario e irónico. El sujeto poético ejerce un posicionamiento rebelde frente al lenguaje. El empleo de minúsculas para los nombres propios y la supresión de mediadores lógicos en los versos son también un signo de la nueva actitud de esta poesía - que toma como influencia los aportes técnicos de la generación beat-. Atendemos a un discurso irónico y urbano que tiene el mismo registro informal y acelerado que el rock ${ }^{7}$.

Encontramos otra muestra de la coloquialidad transgresora del lenguaje rock en los siguientes versos extraídos del poema «Los negros hacían noticia en los diarios», aparecido en el poemario Dedeálade, de Raúl Mendizábal:

me atrevo a preguntar si hoy día nomás en el barrio la señora viuda de lennon podrá conseguir más de cinco sonrisas me pregunto si en su hermoso barrio podrá conseguir más de tres tan solo si podría dejar de botar humo de costado si absorber mi vaso de leche si john patear los claveles y yo como un huevón pateando geranios detrás $(2004$, p. 27)

En los versos citados se aprecia que se construye un lenguaje conversacional, que toma términos empleados coloquialmente en la ciudad y que normalmente podrían considerarse simples, pero que, al encontrarse insertos en un texto poético, adquieren una nueva significación. Las expresiones «hoy día nomás», «botar humo de costado» y «yo como un huevón pateando geranios» reflejan una actualización del lenguaje manifestada en una conciencia juvenil y urbana que responde al nuevo paradigma estético que ya se ha mencionado. Se trata de un testimonio contemporáneo, de una historia oral. De nuevo la ausencia de mayúsculas y de mediadores lógicos revela una transgresión de las reglas de ortografía. Es importante pensar en qué tipo de público es al que apunta esta poesía, pues deberán ser lectores que puedan comprender y compartir el sentido

7 Sobre este lenguaje acelerado con un particular registro coloquial, ha declarado Roger Santiváñez en una entrevista a Rodrigo y Santiago Vera: «yo había visto que el lenguaje más extremo coloquialmente hablando estaba en las calles. Busqué así relacionarme con las esquinas de los barrios, escuchar a la gente hablar y empaparme de ese lenguaje. Para mí la efervescencia, la creatividad más interesante del lenguaje era el lenguaje lumpen. Y como yo andaba metido en la droga tenía contacto con el lumpen, que era para mí un contacto interior» (2016). Lo conversacional surge en la poesía de Santiváñez luego de su encuentro con la jerga de las calles. Notamos que la poesía rockera se alimenta de estos referentes cotidianos. 
de esta coloquialidad, su carga simbólica y contracultural, así como su cuota humorística; lectores que se inserten en la mecánica informal que plantea el poema.

\section{Conclusiones}

Tras realizar el análisis de los poemas seleccionados, podemos llegar a la conclusión de que el rock constituyó la base principal en la formación de un nuevo registro expresivo poético para la generación de 1968. Este registro, al que hemos denominado lenguaje rock, posee una serie de características ligadas al discurso de rebeldía y vitalismo que trajo consigo dicho género musical. Así, hablamos de una escritura rockera cuyas principales características son tres: una marcada heterodoxia, la formación de una identidad juvenil y hedonista, y la exaltación del presente.

Esta investigación permite concluir, además, que los enfoques interdisciplinarios ofrecen una visión amplia de la relación entre dos o más artes, y el contraste que se genere entre ellas puede dar paso a valiosa y novedosa información. Por ello, se plantea la necesidad de que exista en el Perú una crítica literaria que aborde más a menudo las formas de relación entre las artes, y se considera que aún existe mucho por investigar en relación con la escritura de la generación de 1968.

\section{Contribuciones}

Lisa Carrasco La Cruz ha participado en la concepción del artículo, la recolección de datos, su redacción y aprobación de la versión final.

\section{Fuentes de financiamiento}

Propias.

\section{Conflictos de intereses}

Ninguno 


\section{REFERENCIAS BIBLIOGRÁFICAS}

Alemany, C. (1997). Para una revisión de la poesía conversacional. Alma Mater, 13, pp. 49-55.

Alemany, C. (2015). La oveja roja de la poesía: poética coloquial (comunicante, según Benedetti) en América Latina. Biblioteca Virtual Miguel de Cervantes. Recuperado de http://www.cervantesvirtual.com/obra-visor/ la-oveja-roja-de-la-poesia-poetica-coloquial-comunicante-segun-benedetti-en-america-latina-783292/html/20326d13-039a-4664-8f71-7aa8a6aaf6da_2.html\#PagFin

Bangs, L. (1988). Psychotic Reactions and Carburetor Dung. Nueva York: Random House.

Baudelaire, C (2013). El pintor de la vida moderna. Madrid: Taurus.

Cantizano, B. (2005). Poesía y música, relaciones cómplices. Espéculo. Recuperado de https://pendientedemigracion.ucm.es/info/especulo/numero30/poemusi.html

Carrasco, L. (2018). Entrevista a Roger Santiváñez. Molok. Recuperado de: wWw.revistamolok.com

Chueca, L. (2000). Alcances y límites del proyecto vanguardista de Hora Zero. Recuperado de http://lospoetasdelcinco.cl/20/Ensayo/luis_chueca. html

Chueca, L. (2009). ¿La hegemonía de lo conversacional? Notas para continuar una discusión. Intermezzo Tropical, 6-7, pp. 134-140.

Copland, A. (1955). Cómo escuchar la música. Ciudad de México: Fondo de Cultura Económica.

Fernández Retamar, R. (1975). Antipoesía y poesía conversacional en Hispanoamérica. En Para una teoría de la poesía hispanoamericana y otras aproximaciones (pp. 111-126). La Habana: Casa de las Américas.

Fouce, H. (2015). La música pop y rock. Barcelona: UOC.

Friedrich, H. (1959). La estructura de la lírica moderna. Barcelona: Seix Barral.

Gilett, C. (2008). Historia del rock: el sonido de la ciudad. Barcelona: Robinbook.

Goldáraz, J. (2005). La música del siglo XX. Madrid: Dykinson.

Griffiths, P. (2006). Breve historia de la música occidental. Madrid: Akal.

Hormigos, J. (2010). La creación de identidades culturales a través del sonido. Comunicar, 34, pp. 91-98.

Hobsbawm, E. (1998). Historia del siglo XX. Buenos Aires: Grijalbo. 
Huamán, R. (2006). «Alcanzando lo inalcanzable: La poesía de Óscar Málaga. Cyber Humanitatis, 38. Recuperado de https://web.uchile.cl/vignette/ cyberhumanitatis/CDA/texto_simple2/0,1255,SCID\%253D18520\%2526IS ID\%253D648,00.html

Instituto Nacional de Estadística e Informática (2001). Perú: estimaciones y proyecciones de población, 1950-2050. Recuperado de: https://www.inei. gob.pe/media/MenuRecursivo/publicaciones_digitales/Est/Lib0466/Libro.pdf

Landínez, J. P. (2014). La influencia de la cultura rock sobre los movimientos de protesta gestados en la década de los sesenta en los Estados Unidos (tesis de pregrado). Universidad Colegio Mayor de Nuestra Señora del Rosario, Bogotá.

Luchting, W. (1977). Escritores peruanos, qué piensan, qué dicen. Lima: Ecoma.

Mora, T. (2009). Hora Zero: los broches mayores del sonido. Lima: Fondo Editorial Cultura Peruana.

Orihuela, C. (2006). La poesía peruana de los 60 y 70: Dos etapas en la ruta hacia el sujeto descentrado y la conversacionalidad. Acontracorriente, 4(1), pp. 67-85.

Oviedo, J. M. (1973). Estos 13. Lima: Mosca Azul Editores.

Piñeiro, E. (2009). Paz, amor y rock and roll: cultura y contracultura juvenil en la década del 60. Ponencia presentada en XII Jornadas Interescuelas Departamentos de Historia. Universidad Nacional del Comahue. Recuperado de http://bibliotecadigital.uca.edu.ar/repositorio/contribuciones/ paz-amor-rock-and-roll-cultura.pdf

Pimentel, J. (1973). Ave Soul. Madrid: Colección El Rinoceronte.

Ramírez Ruiz, J. (1971). Un par de vueltas por la realidad. Lima: Ediciones del Movimiento Hora Zero.

Rosas Ribeyro, J. (2007). Estación reunida, «el grupo sin grupo»: una aventura político/poética. Sol Negro, 2.

Ruiz, A. (2014). No es solo rocanrol: el lenguaje de la ciudad. Lima: edición del autor.

Sánchez Hernani, E. (1985). Banda del sur. Lima: Los Reyes Rojos.

Santiváñez, R. (2006). Dolores Morales de Santiváñez. Lima: Hipocampo.

Santos, S. (2001). Música general. Madrid: Firmas Press.

Silva, G. (2017). Por ella, por la escena: la construcción de la identidad juvenil de los (chiki) punks de Lima (tesis de pregrado). Pontificia Universidad Católica del Perú, Lima. 
Sorrow. (2010). Poesía y rock. El Batiscafo Rojo. Recuperado de http://elbatiscaforojo.blogspot.pe/2010/03/poesia-y-rock.html

Torres, C. (2006). Rock y poesía peruana: una historia secreta. Ómnibus, 12.

Torres, C. (2009). Demoler. El rock en el Perú. 1965-1975. Lima: Planeta.

Torres, C. (en prensa). Hacia la era de acuario. Molok.

Vera, R. y Vera, S. (2016). Escribo para llegar a todo corazón que se distinga: Entrevista a Roger Santiváñez. Ánima Lisa. Recuperado de: http:// animalisa.pe/entrevistas/escribo-llegar-corazon-se-distinga-entrevistaroger-santivanez/

Verástegui, E. (2004). En los extramuros del mundo. Lima: Fondo Editorial de Cultura Peruana.

Verástegui, E. (2017). Bodegón. Poemas recuperados 1973-1976. Lima: Vallejo \& Co.

Vogel, A. (2018). Rock ' $n$ ' roll: el ritmo que cambió el mundo. Madrid: Ediciones.

Yrigoyen, J. C. y Porcile, R. (Eds.). (2016). Canciones desentonadas y alegres aterrizajes para evitar el suicidio. Óscar Málaga (1968-1973). Lima: Apollo Studio.

Yrigoyen, J. C. y Torres, C. (2010). Poesía en rock. Una historia oral. Perú 1966-1991. Lima: Altazor. 